\title{
Dermoscopy in the diagnosis of juvenile xanthogranuloma*
}

\author{
Thaís Erance de Oliveira ${ }^{1}$ \\ Lismary Aparecida de Forville Mesquita ${ }^{1}$
}

\author{
Roberto Gomes Tarlé1,2
}

\section{DOI: http:/ / dx.doi.org/10.1590/abd1806-4841.20186849}

Abstract: Juvenile xanthogranuloma is the most common form of non-Langerhans cell histiocytosis. It manifests clinically as a red-yellow papule, usually showing spontaneous remission. The diagnosis is based on clinical and histological findings. We report the use of dermoscopy ("setting sun" pattern) as an adjuvant tool in the diagnosis of juvenile xanthogranuloma in a female patient presenting with a 2-month history of a pre-auricular papule.

Keywords: Histiocytosis; non-Langerhans cell; Xanthogranuloma, juvenile

\section{CASE REPORT}

We report the case of a 27 -year-old female patient, presenting with a left pre-auricular asymptomatic erythematous papule for two months (Figure 1). The patient was previously submitted to shaving and electrocoagulation, but experienced recurrence in less than one month. Her personal and family histories revealed no relevant findings.

Dermatological examination revealed a well-defined erythematous papule, $7 \mathrm{~mm}$ in diameter, with a discrete yellowish center and thin scaly halo, located in the left preauricular region (Figure 2). The lesion was not adhered to the deep plans and no enlarged lymphnodes were palpated.

On dermoscopy, we observed a red-yellow center and a discrete erythematous halo, characterizing the "setting sun" pattern, as well as fine and branched telangiectasias, characteristic features of juvenile xanthogranuloma (JXG) (Figure 3).

The lesion was excised under local anesthesia followed by simple suture of the surgical wound.

Histopathological examination revealed localized dermal proliferation of xanthomatous macrophages, sometimes multinucleated, interspersed with mixed inflammatory infiltrate and fibroblasts (Figures 4 and 5). These findings, in correlation with clinical examination and dermoscopy, supported the diagnosis of JXG.

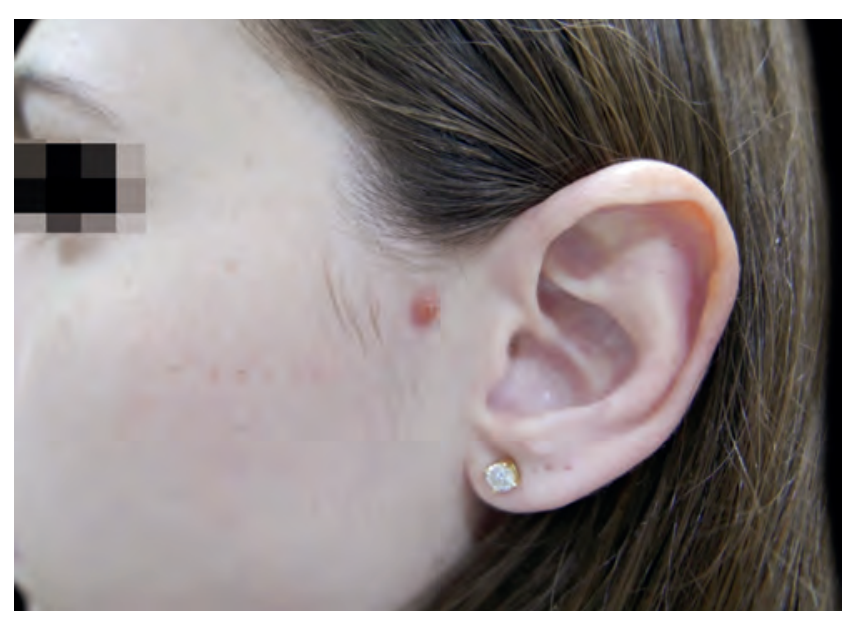

FIgURE 1: Erythematous papule, $7 \mathrm{~mm}$ in diameter, in the left preauricular region

Received on 21.12.2016.

Approved by the Advisory Board and accepted for publication on 03.02.2017.

* Work performed at the Dermatology Service of the Hospital Santa Casa de Curitiba - Curitiba (PR), Brazil.

Financial support: None.

Conflict of interest: None.

1 Dermatology Department at Hospital Santa Casa de Curitiba - Curitiba (PR), Brazil.

2 Discipline of Dermatology at Pontifícia Universidade Católica do Paraná (PUC-PR) - Curitiba (PR), Brazil.

\section{MAILING ADDRESS:}

Thaís Erance de Oliveira

E-mail: tata_jipa@hotmail.com 


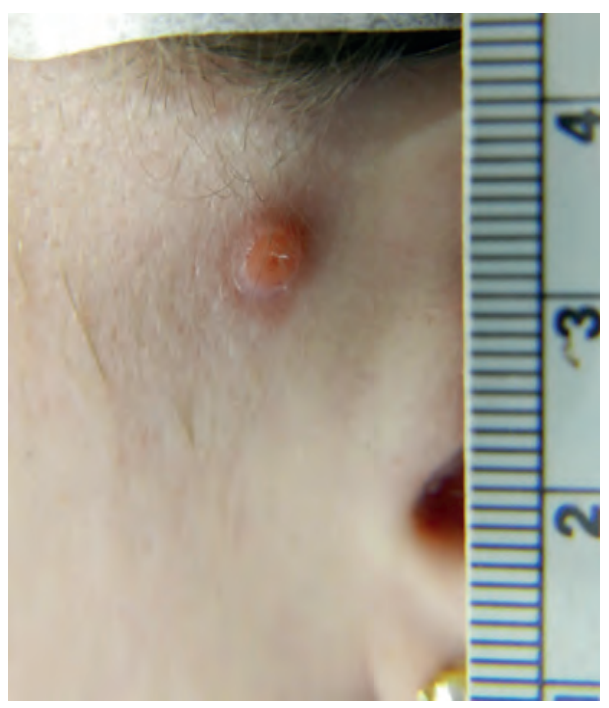

FigURE 2:

Well-defined erythematous papule, with a discrete yellowish center and thin scaly halo

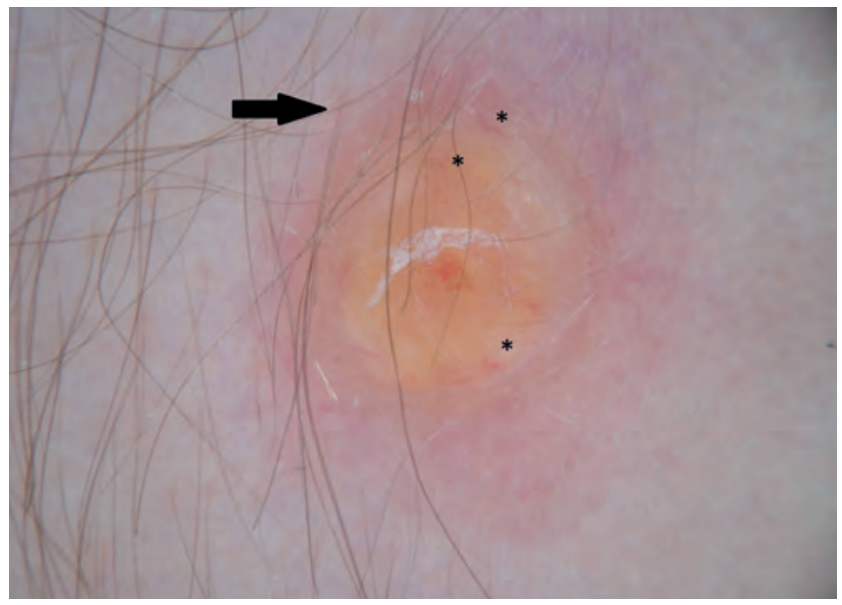

Figure 3: Dermoscopy showing a papule with yellow-orange center and an erythematous halo (arrow), characterizing the "setting sun" pattern, with presence of arboriform telangiectasias (asterisk)

Complete blood cell count, lipidogram, computed tomography of the chest and abdomen, and ophthalmologic evaluation were within normal limits.

\section{DISCUSSION}

Histiocytosis encompasses a group of rare heterogeneous diseases of unknown cause. They are characterized by the proliferation of histiocytes and are classified by the component cells that accumulate in the affected tissue or organ. In Langerhans cell histiocytoses (LCH) there is a predominance of CD1a+, langerin+, and S100+ cells; in non-Langerhans cell histiocytoses (non-LCH), there is a predominance of histiocytes that do not fit into this phenotypic profile. ${ }^{1}$

The Histiocyte Society, reviewing the classification of histiocytoses, proposes the division into five groups: (1) Langerhans-related, (2) cutaneous and mucocutaneous, (3) malignant histiocytoses, (4) Rosai-Dorfman disease, and (5) hemophagocytic lymphohistiocytosis and macrophage activation syndrome. ${ }^{2}$

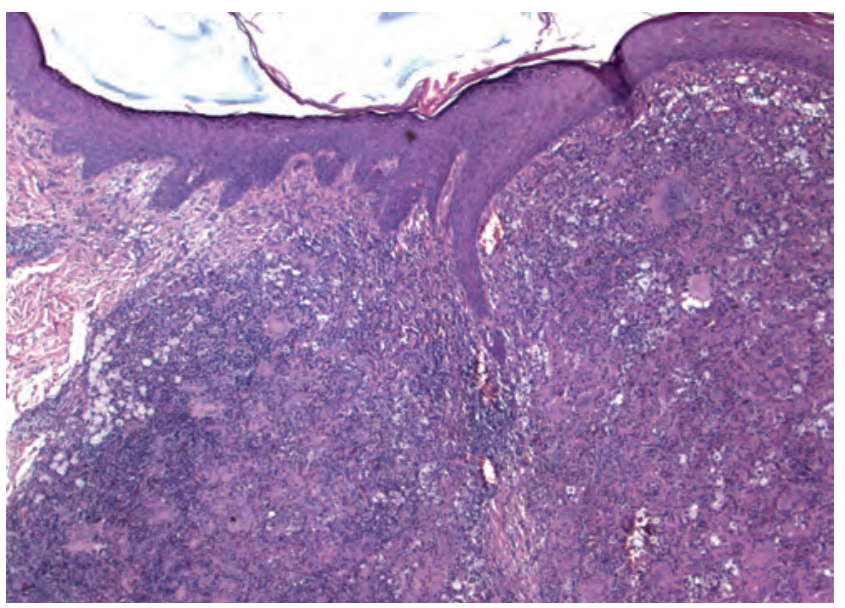

FIGURE 4: Localized dermal proliferation of xanthomatous macrophages, sometimes multinucleated, interspersed by mixed inflammatory infiltrate and fibroblasts, compatible with the diagnosis of juvenile xanthogranuloma (Hematoxylin \& eosin, X40)

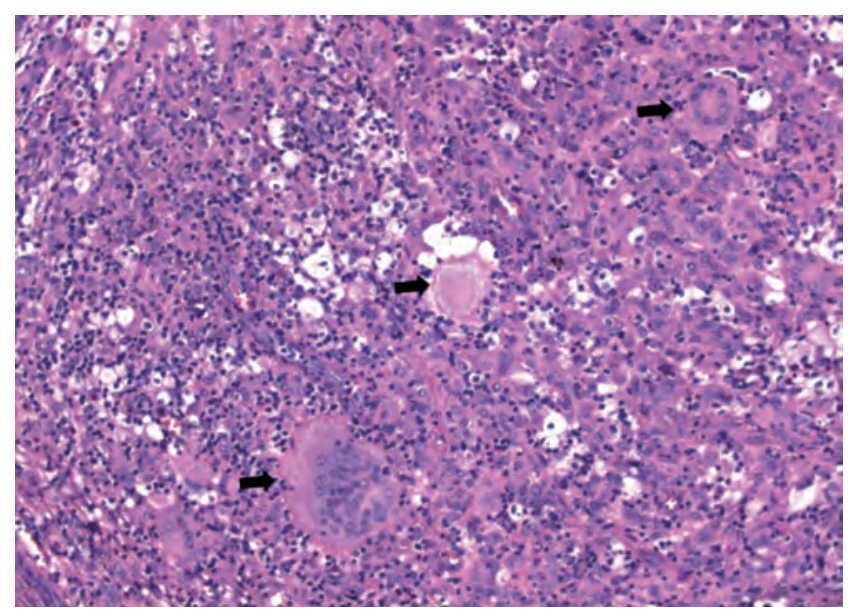

FIGURE 5: Presence of mixed inflammatory infiltrate and Touton cells (arrows), (Hematoxylin \& eosin, X100)

JXG is the most common variant of non- $\mathrm{LCH}{ }^{3}$ It may be present at birth in $5-17 \%$ of the cases and in $40-70 \%$ of cases in the first year of life. In infancy, there is a male predominance in a ratio of 1.5:1, with a tendency to spontaneous regression, which may result in atrophy and hyperpigmentation. ${ }^{1,3,4}$ Although the term juvenile xanthogranuloma is used, adult cases can occur, especially in patients between 20 and 30 years of age, with no sex predilection or spontaneous regression. ${ }^{3,5}$

It manifests clinically as a single, well-defined papule or nodule, affecting mainly the head and neck. ${ }^{6}$ In the early stages, it has a pink to red coloration with variable yellowish tones and, in a later stage, it acquires a brownish-yellow coloration and may develop telangiectasias in the skin surface. ${ }^{3}$

Extracutaneous involvement occurs in $5-10 \%$ of the cases, the eye being the most common affected site. ${ }^{1,3}$ However, the incidence of ocular involvement in patients with exclusively cutaneous JXG is low $(0.3-0.5 \%)$, and does not warrant routine eye examina- 
tions. ${ }^{3}$ Liver, lung, spleen, and other organs may also be involved..$^{1,3}$ Most systemic lesions resolves spontaneously. Investigation is only recommended in the presence of clinical symptoms. ${ }^{7}$ JXG may be associated with other diseases, such as neurofibromatosis type 1 and juvenile chronic myeloid leukemia. ${ }^{1,3}$

Dermoscopy is a noninvasive technique that has been used in the diagnosis of JXG. The pattern described as setting sun is characterized by a yellow-orange central area, which may show areas of lighter yellow, correlating with the dermal xanthogranulomatous infiltrate, and an erythematous halo, which may occur at any stage of evolution., ${ }^{4,8}$ Linear telangiectasias have also been described, as observed in the present case. Therefore, dermoscopy with polarized light or the absence of pressure in dermoscopy with immersion oil is important for its observation. ${ }^{9}$ Other non-specific characteristics found include discrete pigment network, whitish streaks indicating areas of fibrosis, and fine, branched vessels.

\section{REFERENCES}

1. Weitzman S, Jaffe R. Uncommon histiocytic disorders: the non-Langerhans cell histiocytoses. Pediatr Blood Cancer. 2005:45:256-64.

2. Emile JF, Abla 0, Fraitag S, Horne A, Haroche J, Donadieu J, et al. Revised classification of histiocytoses and neoplasms of the macrophage-dendritic cell lineages. Blood. 2016;127:2672-81.

3. Hernandez-Martin A, Baselga E, Drolet BA, Esterly NB. Juvenile xanthogranuloma J Am Acad Dermatol. 1997;36:355-67.

4. Palmer A, Bowling J. Dermoscopic appearance of juvenile xanthogranuloma Dermatology. 2007;215:256-9.

5. Aburezq $H$, Jaeger $M$, lyengar $P$, Zuker $R$. Juvenile xanthogranuloma of the nose The Canadian journal of plastic surgery. Can J Plast Surg. 2004;12:198-200.

6. Luz FB, Gaspar AP, Kalil-Gaspar N, Ramos-e-Silva M. Os histiócitos e as histiocitoses não Langerhans em dermatologia. An Bras Dermatol. 2003;78:99-118.
JXG is histopathologically characterized by dense pleomorphic histiocytic dermal infiltrates, with a predominance of vacuolated cells at earlier stages and posterior xanthomatous cells. In the later stages, Touton-type multinucleated xanthomatous cells (with provision of nuclei in the periphery of the cytoplasm) are found more easily, which, although characteristic, are non-specific., 3,70

Due to the benign nature of the disease and its tendency to regression, conservative treatment may be adopted. ${ }^{4}$ Dermoscopy is an important aid in the noninvasive diagnosis of JXG. Surgical excision can be performed for complete removal of the lesion and diagnostic confirmation.
7. Sivapirabu G, Sugo E, Wargon 0. Juvenile xanthogranuloma: challenges in complicated cases. Australas J Dermatol. 2011;52:284-7.

8. Hussain SH, Kozic H, Lee JB. The utility of dermatoscopy in the evaluation of xanthogranulomas. Pediatr Dermatol. 2008;25:505-6.

9. Rubegni P, Mandato F, Fimiani M. Juvenile xanthogranuloma: dermoscopic pattern. Dermatology. 2009;218:380; author reply 381.

10. Song M, Kim SH, Jung DS, Ko HC, Kwon KS, Kim MB. Structural correlations between dermoscopic and histopathological features of juvenile xanthogranuloma. J Eur Acad Dermatol Venereol. 2011;25:259-63.

How to cite this article: : Oliveira TE, Tarlé RG, Mesquita LAF. Dermoscopy in the diagnosis of juvenile xanthogranuloma. An Bras Dermatol. 2018;93(1):138-40. 